\title{
JORNAL DAS MOÇAS (1926-1932): imprensa feminina no sertão norte-rio-grandense
}

\author{
Ladies' journal: female press in the State of Rio Grande do Norte, Brazil
}

\author{
Manoel Pereira da Rocha Neto \\ Jornalista e Doutor em Educação pela Universidade Federal do Rio Grande do Norte. Professor do curso de Comunicação Social \\ da Universidade Potiguar (UnP). Natal, RN - Brasil, e-mail: manuneto@yahoo.com
}

\begin{abstract}
Resumo
O presente artigo tem como objetivo investigar o Jornal das Moças (1926-1932), enfatizando a presença das professoras Georgina Pires, Dolores Diniz e Júlia Augusta de Medeiros, mulheres que produziram o jornal em Caicó, no Rio Grande do Norte. Analiso as práticas de escrita dessas mulheres, salientando os aspectos educacionais, a questão de gênero e as relações que se estabelecem na sociedade, na tentativa de contribuir com a historiografia da educação no Brasil, durante a década de 20. Como fonte, foram utilizados exemplares disponíveis do Jornal das Moças, entrevistas com historiadores, familiares e pessoas vinculadas às citadas professoras. Evidencia-se que essas mulheres fizeram o jornal acontecer, numa época em que a configuração social de sua comunidade reservava à mulher apenas o domínio do espaço privado. Os resultados da pesquisa balizam para constatar que esse impresso foi um veículo de comunicação inovador, tornando-se um dos instrumentos dos quais as mulheres puderam extrapolar as barreiras do seu espaço, atuando na imprensa, território predominantemente masculino. Inferindo no cotidiano por meio dos seus textos jornalísticos e dos movimentos culturais, educacionais e comportamentais, essas mulheres teceram suas conquistas, ocupando posições de destaque no campo da educação e da comunicação.
\end{abstract}

Palavras-chave: Jornalismo feminino; Gênero; Imprensa.

\section{Abstract}

The current article intends to analyze the "Jornal das Moças" (Lady's journal) (1926 1932) emphasizing the presence of teachers Georgina Pires, Dolores Diniz and Júlia Augusta de Medeiros, women who produced the journal at Caicó city, state of Rio Grande do Norte (Brazil). I analyze the writing practices from these women, accentuating the educational aspects, the gender question and the relations established at society in the try to contribute with education's historiography in Brazil, during the 1920's decade. I use as source, some 
reminiscent copies from Jornal das Moças, interview with historiographer, members from their families and people connected with these teachers. I observed that those women made the journal happens, in a time with a social configuration which designates do woman just the domain of private territory. The results of research bounds to verify this journal was a innovate communication vehicle, which became one of the instruments to women extrapolate the barriers from their space, acting in the press, territory where men used to prevail. Inferring at quotidian through their journalists pieces and through cultural, educational and behavior movements, these women weaved their conquests, occupying detached positions in education and communication fields.

Keywords: Female journalism; Gender; Press.

\section{INTRODUÇÃO}

O presente artigo faz parte da dissertação de mestrado intitulada: Jornal das Moças (19261932): educadoras em Manchete, da Base de Pesquisa Gênero e Práticas Culturais: abordagens histórica, educativas e literárias, do Programa de Pós-Graduação em Educação da Universidade Federal do Rio Grande do Norte, sob a orientação da professora Maria Arisnete Câmara de Morais.

A pesquisa tem como objetivo relatar a trajetória de mulheres que contribuíram para a educação no estado do Rio Grande do Norte, fazendo uma análise da participação feminina na imprensa norte-rio-grandense na década de 20. A pesquisa investiga o Jornal das Moças (19261932), enfatizando a presença das professoras Georgina Pires, Dolores Diniz e Júlia Augusta de Medeiros, que fizeram o jornal acontecer. O motivo de pesquisar essa publicação surgiu do caráter inovador e pioneiro de suas técnicas jornalísticas.

O referido jornal era uma publicação semanal, dedicada ao interesse da mulher. Sua circulação iniciou-se no dia 07 de fevereiro de 1926, na cidade de Caicó, no Rio Grande do Norte. Além de editado pela professora Georgina Pires e gerenciado por Dolores Diniz, o periódico contava também com as redatoras Júlia Medeiros, Santinha Araújo, Maria Leonor Cavalcante, Julinda Gurgel, como também várias moças da sociedade caicoense. Esse grupo de mulheres escreveu sobre literatura, humorismo e críticas com relação à condição da mulher na sociedade norte-rio-grandense. Colaboravam, também, para o jornal os senhores Renato Dantas, Janúncio Bezerra da Nóbrega e José Gurgel de Araújo. A folha enquadrava-se nos padrões dos grandes jornais da época no estado, no que se refere às técnicas gráficas, como por exemplo, os periódicos A República, de Natal, e o Jornal do Seridó (1927-1929) de Caicó, entre outros.

Do tipo tablóide, com $28 \mathrm{~cm}$ de largura por $38 \mathrm{~cm}$ de altura, com cerca de três colunas em cada página - as primeiras edições tinham o formato de duas colunas apenas - e impresso em papel jornal, com folhas soltas dobradas em forma de caderno, o periódico mantinha uma redação permanente e sua distribuição era feita através de venda avulsa nas bancas e por assinatura. Fato esse inédito para um jornal feminino no Rio Grande do Norte, visto que os jornais editados por mulheres, em sua grande maioria, eram manuscritos, ao passo que o tablóide de Caicó já utilizava técnicas jornalísticas, como a diagramação, formato de três colunas, distribuição nas bancas da cidade, como também as assinaturas de seus exemplares. Essas assinaturas tinham "os seguintes valores; anual: 10 mil réis; semestral: 8 mil réis; trimestral: 4 mil réis e a venda avulsa, 200 réis" (MELO, 1987, p. 28).

O Jornal das Moças registra o sucesso dessas assinaturas, por meio da coluna de cartas. Publicou em suas edições correspondências de seus leitores, comprovando a boa aceitação de jornal em Caicó e também em outras cidades do estado. Várias cartas foram enviadas à redação do jornal, felicitando e parabenizando o corpo redacional pela iniciativa do impresso em irradiar o pensamento das mulheres caicoenses.

Leitores das cidades de Natal, Ceará-Mirim e Lajes, entre outros municípios norte-riograndenses, demonstraram a sua satisfação ao ler o jornal, bem como o interesse de tornarem-se leitores assíduos do jornalzinho, como as professoras Helena e Josepha Botelho, da cidade de Ceará-Mirim: 
Ao distinto corpo redacional do "Jornal das Moças". Helena e Josepha agradecem a remessa do seu muito apreciado jornalzinho. Aliamos os nossos sinceros aplausos e a nossa inteira solidariedade, fazendo votos de prosperidade pela sua novel existência. Assinam Helena e Josepha Botelho. (JORNAL DAS MOÇAS, 11 abr. 1926, p. 2 ).

A professora Berthilde Guerra, residente em Natal, mostrava-se interessada na leitura periódica do jornal:

Cara amiguinha do Jornal das Moças, saudações cordiais. É com grande regozijo que tenho lido vosso interessante jornalzinho. Lamento ser já tão tarde para apresentar os meus efusivos parabéns à jovem e distinta falange que tão nobremente vem combatendo por um ideal tão sublime que é o amor, a cultura das letras [...] aproveito a oportunidade para pedir uma assinatura do vosso jornalzinho para cujo fim envio a respectiva importância. As vossas prezadas ordens, amigas administradoras. Assina Berthilde Guerra. (JORNAL DAS MOÇAS, 23 maio 1926, p. 4).

Da cidade de Lajes, as redatoras do Jornal das Moças receberam, de Ilnah Pereira, os parabéns pela vitória alcançada:

Tendo recebido os números do novo órgão que circula na próspera Caicó [...] é impossível deixar de dizer algo às amiguinhas que tanto prazer proporcionam com a leitura do muito apreciado jornalzinho. É bem de elogios o sonho que tão digna plêiade de senhoritas caicoenses levou a efeito. Levo, pois, ás dirigentes de bem acolhido órgão, o meu voto de prosperidade e os sinceros parabéns pela vitória alcançada. (JORNAL DAS MOÇAS, 23 maio 926, p. 4).

O impresso extrapolou as fronteiras do município de Caicó, abarcando um número maior de leitores no estado e era alvo de elogios em outros veículos de comunicação. A edição do Jornal das Moças datada de 4 de abril de 1926, publica uma nota veiculada no Jornal do Sertão, editado na cidade de Patos, na Paraíba:

Recebemos a gentil visita do Jornal das Moças, mimoso porta-voz das inteligentes filhas de Caicó, no vizinho estado do norte. O Jornal das Moças, cujo corpo redacional é composto por Georgina Pires, Dolores Diniz, entre outras senhorinhas, traz seleta colaboração que autoproclama o amor das moças caicoenses pelas causas do espírito [...]. O interessante semanário apresenta feição material muito atraente. (JORNAL DAS MOÇAS, 04 abr. 1926, p. 2).

A imprensa da capital norte-rio-grandense também fez registro do jornalzinho nas suas páginas, por meio do jornal A Imprensa, diário dirigido por Luís da Câmara Cascudo. A edição do Jornal das Moças, de 18 de abril de 1926, registra:

A Imprensa, de Natal, importante diário dirigido pelo brilhante intelectual patrício Dr. Luís da Câmara Cascudo [...], publicou após receber a edição de número quatro do nosso jornalzinho: "Visitou-nos o número 4 do Jornal das Moças, órgão literário, humorístico e crítico que se publica em Caicó, sob a direção e gerência de nossas ilustres confreiras Georgina Pires e Dolores Diniz. O Jornal das Moças é bem feito, e apesar de pequenino traz leitura variada, abordando assuntos de valor (JORNAL DAS MOÇAS, 18 abr. 1926, p. 4).

Nas páginas do Jornal das Moças eram publicadas curiosidades da cidade, artigos e crônicas de interesse feminino, literatura, poesias, pensamentos, colunas sociais, acontecimentos da sociedade caicoense, amenidades em geral, notas diversas e questionamentos sobre a condição da mulher na sociedade.

$\mathrm{Na}$ sua edição inaugural, o periódico publicou na primeira página um artigo intitulado o Jornal das Moças, assinado por Renato Dantas, um dos poucos colaboradores do sexo masculino. $\mathrm{O}$ mesmo versa sobre a importância daquele jornal:

Será este um semanário de caráterindependente, noticioso, e contará com assídua colaboração das nossas conterrâneas. Como se trata de um órgão fundado por moças de nossa melhor sociedade, certo ele trará ensejo para o desenvolvimento da mulher caicoense, que já se há afirmando propendente às lides jornalísticas. Caicó está, portanto, de parabéns com a criação do Jornal das Moças (DANTAS, 1926, p. 1).

Percebe-se a importância do impresso que acabara de nascer, tornando-se o veículo das idéias e opiniões das moças caicoenses. Na mesma edição de estréia da folha, em um outro artigo, 
intitulado Surtos de progresso, por sua vez sem autoria, ressalta também esse acontecimento:

Com o desenrolar dos tempos modernos e progressistas, a mulher caicoense compreendeu que havia um vácuo a preencher no mundo literário do Caicó. E por isso, fundou o seu jornal [...]. O jornalzinho viverá porque para tal foi emprestado o brilho, a tenacidade e a força de vontade desse punhado de conterrâneas, que certamente lhe vão bordar as colunas dos mais agradáveis artiguetes (SURTOS DE PROGRESSO, 1926, p. 3).

Esse jornal possuía como epígrafe: Literatura, humorismo e crítica, que traduzia o tripé de sua linha editorial. Ao analisar diversos exemplares, percebo que era comum o uso de notinhas e pensamentos de caráter crítico, relacionados ao comportamento masculino. As editoras faziam uso desses artifícios para completar a diagramação do jornal e também como forma de estimular e divulgar as assinaturas daquele periódico:

A mulher é o símbolo da alegria e da paz; a formosura de todas as formosuras; o homem é uma criança traquina e volúvel, que se deixa arrastar ao impulso de um pequeno capricho (JORNAL DAS MOÇAS, 23 fev 1928, p. 4). O homem tem três caracteres: o que tem, o que mostra e o que pensa ter. A mulher, pelos seus sentimentos de bondade, apresenta caracteres que não se podem descrever (JORNAL DAS MOÇAS, 31 jul. 1926, p. 2).

Assine o Jornal das Moças, ele estimula o desenvolvimento intelectual dos seus filhos (JORNAL DAS MOÇAS, 15 ago. 1926, p. 3).

O jornal caicoense não inova apenas na linha editorial e na sua forma gráfica. Havia também no impresso uma página de anúncios, que circulou de fato após três meses da sua fundação. Investigando os exemplares daquele período, percebo que isso aconteceu a partir da edição de 23 de maio de 1926.

Com a boa aceitação e a circulação nas grandes rodas sociais da cidade, causando curiosidade e admiração das moças e senhoras, o comércio de Caicó encontrou nas páginas do Jornal das Moças o meio ideal para divulgar seus produtos para o segmento feminino. Eram veiculados anúncios de lojas de fazendas finas, de chapéus, de guarda-sol e adornos para tornar mais bela da cidade. Endereços da moda e da elegância como a Casa da Torre, Casa Dias \& Araújo, Casa Soares Araújo e Loja Avenida e até serviços odontológicos do cirurgião Dentista J. Freire e do produto Dentefácil, vendido na Farmácia Gurgel. Esses anúncios circularam a partir da edição de 23 de maio de 1926.

Instalada em prédio confortável, chama a atenção da distinta família caicoense para o variado sortimento de fazendas finas, artigos da última moda: charmeuse, crepes da China, voiles bordados, organdys bordados [...] lindo sortimento de chapéus, última novidade para senhoras, senhoritas e homens. Uma visita à loja Avenida é economizar dinheiro e comprar com satisfação.

O dentista J. Freire, cirurgião dentista pela Faculdade de Medicina do Rio de Janeiro, possuindo completo instrumental de gabinete e prótese, pratica com absoluta segurança: dentaduras duplas, coroas de porcelana sintética, ouro e platina, blocos e incrustações a ouro e porcelana. Extrações sem dor, etc.

Dentefácil, preparado exclusivamente do Dr. Sabino Pinho, premiado em várias exposições do estrangeiro e também com medalha de ouro, no centenário da Independência do Brasil. Facilita a dentição e torna as crianças alegres, sadias, fortes, robustas e bem dormidas. Não sendo do Dr. Sabino é falso. Vende-se na Farmácia Gurgel. (JORNAL DAS MOÇAS, 23 maio 1926, p. 3).

Estes anúncios configuram não apenas o hábito da mulher caicoense em vestir-se elegantemente nos eventos sociais, mas também o costume de usar dentes de ouro e porcelana, como forma de ostentação.

Uma página inteira para anúncios e a frequência dos citados anunciantes caracterizavam o prestígio que o Jornal das Moças detinha na sociedade local. Os anúncios viabilizaram a circulação da folha até meados dos anos de 1930. Com o sucesso do jornal, a mulher de Caicó, teve oportunidade de escrever sobre assuntos de seu interesse. A edição de 28 de fevereiro de 1926, por exemplo, retratava, em uma nota intitulada Colaboração, a vontade e a participação efetiva das moças em colaborar com a folha:

Diante do pequeno espaço para acolher a colaboração distinta das nossas muitas amigas, não publicaremos nenhum artigo que exceda a 
duas tiras de papel almaço. Pedimos também, às distintas colaboradoras, escreverem seus artigos com letra bem legível. Portanto, para que nenhuma fique zangada conosco [...]. (COLABORAÇAO, 1926, p. 3).

Nesse contexto, as mulheres reverberavam pelo 'jornalzinho' suas idéias, pensamentos e seus movimentos culturais. Elas começaram a produzir e participar na imprensa norte-riograndense, de modo mais abrangente.

O sucesso do semanário feminino perdurou até o ano de 1932. Segundo Monteiro (1999, p. 82), ao suspender a circulação do jornal, naquele ano, suas dirigentes deram um balanço no caixa e encontraram um saldo de 120 mil réis, que foi assim distribuído: 100 mil réis para os pobres da localidade de São Vicente e 20 mil réis para Manuel Rodrigues Filho, o tipógrafo do jornal.

Um fato curioso sobre o prédio onde funcionou a tipografia do Jornal das Moças, na praça da Liberdade, diz respeito a um sobrado do século XIX, de linhas arquitetônicas arrojadas. Segundo populares de Caicó, a construção foi colocada abaixo recentemente, por aproximadamente cinquenta homens, na calada da noite, ou seja, anoiteceu e não amanheceu. O motivo da demolição foi a informação de que o referido sobrado faria parte do patrimônio arquitetônico da cidade, a ser preservado. Temendo ficar no prejuízo, o seu proprietário mandou demolir, negociando, posteriormente, o terreno. No local foi erguido um condomínio moderno de quatro andares.

No Brasil, o ápice da imprensa feita pelas mulheres aconteceu no período de 1850 a 1910. Nesta época, os impressos direcionados para as mulheres ganhavam espaço na imprensa, principalmente na carioca, onde jornais como $O$ Jornal das Senhoras (1852), Belo Sexo (1862), Biblioteca das Senhoras (1874), O Bisbilhoteiro (1889), Eco das Damas (1879-1882), Recreio do Belo Sexo (1856), Recreio das Moças (1876-1877), O Direito das Damas (1882) e tantos outros, circularam no Rio de Janeiro (MORAIS, 2002, p. 69).

Segundo Buitoni (1986, p. 37), o primeiro jornal de caráter feminino no Brasil nasceu no Rio de Janeiro e chamava-se O Espelho Diamantino (1827). Este periódico continha política, literatura, belas-artes e modas. Em Recife, surgiu o possível segundo periódico feminino brasileiro, denominado
O Espelho das Brazileiras (1831). Outros se seguiram: Jornal de Variedades (1835), Relator de Novellas (1838). No Rio de Janeiro surge, em 1839, o jornal semestral Correio das Modas (1839-1841) da casa Laemmert, com bastante Literatura, crônica de bailes e teatros e figurinos pintados à mão, oriundos da França. Eram os primeiros passos da participação da mulher na imprensa brasileira.

No Rio Grande do Norte, mais especificamente em Caicó, o Jornal das Moças sempre esteve pautado em abrir espaço para a mulher se fazer presente na vida social e cultural daquele município.

Por meio do meu objeto de pesquisa, o Jornal das Moças, é possível configurar e investigar sobre essas mulheres consideradas anônimas pela História tradicional, mas que dentro de um dado período e local também fizeram suas histórias. Uma História à margem da historiografia oficial, mas que configurada nesta pesquisa demonstra lutas por novas conquistas sociais para a mulher norte-rio-grandense.

\section{REFERÊNCIAS}

BUITONI, Dulcília Schroede. Imprensa feminina. São Paulo: Ática, 1986. (Série Princípios).

COLABORAÇÃO. O Jornal das Moças, Caicó, RN, p. 3, 1926.

DANTAS, Renato. Jornal das moças. O Jornal das Moças, Caicó, 7 fev. p. 1, 1926.

JORNAL DAS MOÇAS. Caicó, 23 fev. p. 4, 1928.

JORNAL DAS MOÇAS. Caicó, 28 fev. p. 3, 1926.

JORNAL DAS MOÇAS. Caicó, 04 abr. p. 2, 1926.

JORNAL DAS MOÇAS. Caicó, 11 abr. p. 2, 1926.

JORNAL DAS MOÇAS. Caicó, 18 abr. p. 4, 1926.

JORNAL DAS MOÇAS. Caicó, 23 maio p. 4, 1926.

JORNAL DAS MOÇAS. Caicó, 31 jul. p. 2, 1926.

JORNAL DAS MOÇAS. Caicó, 15 ago. p. 3, 1926.

MELO, Manoel Rodrigues de. Dicionário da imprensa no Rio Grande do Norte (19071987). São Paulo: Cortez; Natal: Fundação José Augusto, 1987. 
MONTEIRO, Pe. Eymard L'Eraistre. Caicó: subsídios para a história completa do município. 2. ed. Natal: Sebo Vermelho, 1999.

MORAIS, Maria Arisnete Câmara de. Leituras de mulheres no século XIX. Belo Horizonte: Autêntica, 2002.

SURTOS DE PROGRESSO. Jornal das Moças, Caicó, 07 fev. p. 3, 1926.

Recebido: 30/05/2008

Received: 05/30/2008

Aprovado: $01 / 07 / 2008$

Approved: 07/01/2008 